\title{
Neural Topography and Content of Movement Representations
}

\author{
Floris P. de Lange, Peter Hagoort, and Ivan Toni
}

\begin{abstract}
We have used implicit motor imagery to investigate the neural correlates of motor planning independently from actual movements. Subjects were presented with drawings of left or right hands and asked to judge the hand laterality, regardless of the stimulus rotation from its upright orientation. We paired this task with a visual imagery control task, in which subjects were presented with typographical characters and asked to report whether they saw a canonical letter or its mirror image, regardless of its rotation. We measured neurovascular activity with fast event-related fMRI, distinguishing responses parametrically related to motor imagery from responses evoked by visual imagery and other task-related phenomena. By quantifying behavioral and neurovascular correlates of imagery on a trial-by-trial basis, we could discriminate between stimulusrelated, mental rotation-related, and response-related neural
\end{abstract}

\section{INTRODUCTION}

Electrophysiological studies in behaving monkeys have revealed the how parietal and premotor cortex contributes to plan movements of the hand and arm (Crammond \& Kalaska, 2000; Johnson, Coltz, Hagen, \& Ebner, 1999; Shen \& Alexander, 1997; Johnson, Ferraina, Bianchi, \& Caminiti, 1996; Ashe \& Georgopoulos, 1994; Crammond \& Kalaska, 1989). Imaging studies in humans have also investigated neural correlates of movement planning, isolating neurovascular responses during movement preparation in delayed response tasks (Connolly, Goodale, Menon, \& Munoz, 2002; Simon et al., 2002; Thoenissen, Zilles, \& Toni, 2002; Toni, Shah, et al., 2002; Toni, Thoenissen, \& Zilles, 2001; Connolly, Goodale, Desouza, Menon, \& Vilis, 2000; D'Esposito, Ballard, Zarahn, \& Aguirre, 2000; Toni, Schluter, Josephs, Friston, \& Passingham, 1999; Richter, Andersen, Georgopoulos, \& Kim, 1997; Deiber, Ibanez, Sadato, \& Hallett, 1996). However, these studies have not explicitly addressed the nature of the information processes implemented by frontal and parietal regions during the transformation of sensory stimuli into motor responses. Furthermore, these investigations have been based on

University of Nijmegen, The Netherlands activity. We found that specific portions of the posterior parietal and precentral cortex increased their activity as a function of mental rotation only during the motor imagery task. Within these regions, the parietal cortex was visually responsive, whereas the dorsal precentral cortex was not. Response- but not rotation-related activity was found around the left central sulcus (putative primary motor cortex) during both imagery tasks. Our study provides novel evidence on the topography and content of movement representations in the human brain. During intended action, the posterior parietal cortex combines somatosensory and visuomotor information, whereas the dorsal premotor cortex generates the actual motor plan, and the primary motor cortex deals with movement execution. We discuss the relevance of these results in the context of current models of action planning.

the notion that preparing to execute an action evokes its mental representation (Rizzolatti \& Luppino, 2001; Jeannerod, 1997). However, immediate and delayed performances of motor behavior might be controlled by different neural circuits (Rossetti \& Pisella, 2002). For instance, psychophysical studies have shown that providing immediate or delayed responses to sensory stimuli depends on different sensorimotor processes (Bridgeman, Gemmer, Forsman, \& Huemer, 2000; Gentilucci, Chieffi, Deprati, Saetti, \& Toni, 1996; Wong \& Mack, 1981). Neuropsychological studies have shown that, although a patient with visual agnosia could correctly grasp objects only when the movement occurred shortly after stimulus presentation (Goodale, Jakobson, \& Keillor, 1994), a patient with optic ataxia "improved" her grasping performance when a delay was introduced between stimulus and response (Milner, Dijkerman, Pisella, et al., 2001). In this perspective, it is conceivable that the findings of previous studies, exploiting delayrelated responses to operationalize movement preparation, might not generalize to movement representations related to immediate action.

In this study, we aim to characterize not only which regions are implicated in immediate action independently from movement execution, but also how they are implicated. In order to isolate movement represen- 
tations from movement execution without forcing delays in the sensorimotor process, we have appealed to the concept of implicit motor imagery (MI). Several psychophysical studies (Parsons, 1987, 1994; Sekiyama, 1982) have demonstrated that human subjects, when asked to judge the laterality of a rotated image of a hand, solve this task by imagining their own hand moving from its current position into the stimulus orientation for comparison. Here we have used MI as a "tool" to drive subjects to manipulate movement representations, defined as internal models of the goal of an action (Jeannerod, 1994). In this perspective, our manipulation is likely to evoke internal simulation of actions for the purpose of selecting the most biomechanically appealing movement plan, thus allowing for the computation and refinement of the premotor plan (Johnson, Rote, et al., 2002; Johnson, 2000). It is important to note, however, that behavioral and neural correlates of internal simulation of actions may not generalize to movement planning of immediate actions, given that actions were simulated and not carried out.

Subjects were presented with drawings of hands and asked to report whether they were seeing a left hand or a right hand, regardless of the angle of rotation of each stimulus from its upright position. We paired this MI task with a visual imagery (VI) control task in which subjects were presented with typographical characters and asked to report whether they were seeing a canonical letter or its mirror image, regardless of its rotation (Alivisatos \& Petrides, 1997; Shepard \& Cooper, 1982). During task performance, we measured behavioral performance and neural activity with fast event-related fMRI (Friston, Zarahn, Josephs, Henson, \& Dale, 1999). This experimental design allowed us to distinguish responses parametrically related to MI from responses evoked by VI and other task-related phenomena. Crucially, during each trial, we distinguished between neural activity associated with different components, namely, stimulusrelated activity, mental rotation-related activity, and residual response-related activity. We performed two separate control experiments. We investigated the influence of the posture of the subject's own arm on the performance of MI and VI tasks. Furthermore, we assessed muscular activity in the left and right hands during both tasks, to exclude that overt hand movements could have influenced our data. Preliminary results have been presented elsewhere (de Lange, Hagoort, \& Toni, 2003a, 2003b).

\section{RESULTS}

\section{Behavioral Performance}

Reaction time (RT) and error rate (ER) increased with increasing stimulus rotation [rotation: RT, $F(6,30)=$ $29.0, p<.001$; ER, $F(6,30)=6.2, p=.017]$. Subjects were slower and more error-prone in MI than in VI per- formance [task: RT, $F(1,5)=16.3, p=.01$; ER, $F(1,5)=$ $6.5, p=.05]$. Mean response times are illustrated as a function of rotation for both the hand (MI) and the letter (VI) laterality judgment task (Figure 1B). In both tasks, RTs changed as a function of rotation according to a combination of linear and quadratic effects. Crucially, RTs increased as a function of rotation more in MI than in VI [Task $\times$ Rotation interaction: $F(6,30)=$ $10.1, p=.005]$. The RT profile observed during performance of the posture test indicates that the posture of the left hand influenced the hand (MI) but not the letter (VI) laterality judgment task. Figure 1C illustrates the mean RTs as a function of task and rotation across the two positions of the left hand (note that flexions of fingers of the right hand were the only overt movements required by the tasks). It was easier to perform the MI task, but not the VI task, with the left hand perpendicular to the right hand $[\mathrm{MI}-$ posture: $F(1,6.0)=7.47, p=.034 ; \mathrm{VI}-$ posture: $F(1,7.6)=$ $0.070, p=.798]$. However, this differential effect was not due to flooring or ceiling effects, because in both tasks RTs significantly increased with increasing rotation [MI-rotation: $F(6,8.7)=11.2, p=.001$; VI-rotation: $F(6,7.5)=14.0, p=.001]$. EMG measurements excluded the presence of overt hand movements during task performance in the scanner in both tasks, apart from the required finger flexions. Figure 1D illustrates the variability in EMG signal relative to a baseline period across three subjects during stimulus and response epochs. EMG variance increased only for the right hand [main effect of hand: $F(1,816)=441.3, p<.001$ ]. This increase in variance occurred only during the response epoch [epoch: $F(1,816)=519.6, p<.001$; Epoch $\times$ Hand interaction: $F(1,816)=402.7, p<.001]$, and equally so during both tasks [task: $F(1,816)=0.11$, $p>$.7].

\section{Neural Activity}

We modeled neural activity along different points in time, namely, stimulus-related, rotation-related, and (residual) response-related neural activity. We distinguished between activity that was shared by both tasks (common activity, designated by $\cap$ ) and activity that was greater during MI than during VI (differential activity, designated by $>$ ). There were no areas that were more strongly activated during VI than during MI (i.e., VI was contained within MI). This finding indicates that VI was a task adequate to control for general imageryrelated activity. Stereotactic coordinates of voxels showing significant communalities and differences across effects of stimulus, rotation, and response are listed in Tables 1-3. The anatomical location, fitted peak blood oxygen level dependent (BOLD) signal, and parameter estimates of some representative responses are illustrated in Figures 2 and 3. 
Stimulus-related Activity (MIs, VIs):

Anatomical Location

Several cerebral regions showed stimulus-related activity that was unaffected by rotation and response (Table 1). Both tasks evoked similar activity (MIs $\cap$ VIs) in the extrastriate visual cortex (see Figure $2 \mathrm{~A}-\mathrm{C}$ ), left postcentral sulcus, left frontal operculum, anterior cingulate sulcus (bilaterally), posterior hippocampi, and portions of the cerebellum. Stronger stimulus-related activity during MI than VI (MIs > VIs) was found in the right occipital lobe (calcarine sulcus and middle occipital gyrus; Figure 2D-F). Calcarine activity was within the variability range of cytoarchitectonically defined area 17 (Amunts, Malikovic, Mohlberg, Schormann, \& Zilles, 2000). There was no stronger stimulus-related activity during VI than MI (VIs > MIs).

\section{Stimulus-related Activity (MIs, VIs): Hemodynamic Response}

Figure $2 \mathrm{~A}$ and $\mathrm{D}$ illustrates the BOLD peak signal change with respect to baseline across experimental factors for representative cerebral regions. Figure $2 \mathrm{C}$ and $\mathrm{F}$ shows the corresponding parameter estimates for different variance components. The right lingual gyrus (Figure 2AC) was active during performance of both $\mathrm{MI}$ and VI (Figure 2C; "Stimulus" histograms). In contrast, the middle occipital gyrus (Figure 2D-F) showed consistent responses during performance of MI, but not during VI. This differential stimulus-related activity appears to fall in

Figure 1. Task setup and behavioral results. (A) Task setup. Hand drawings (MI, upper row) and typographical characters (VI, lower row) were presented in blocks of 7 trials. Stimuli could be rotated from $0^{\circ}$ to $180^{\circ}$ in $30^{\circ}$ steps. During MI, subjects had to report whether the picture was a left or a right hand. During VI, subjects had to report whether the picture was a canonical letter or its mirror image. Subjects responded by pressing either the left or right button with their right hand. Blocks of MI (gray boxes) and VI (black boxes) were intermixed with a baseline period during which a fixation cross was presented. The numbers indicate blocks of trials within an imaging session. A rapid event-related fMRI design allowed us to distinguish between stimulus-related activity, activity that was a function of rotation and residual response-related activity. (B) Response times (mean $\pm S E M$ ) during MI (gray triangles) and VI (black diamonds) as a function of the rotation of the stimuli. Rotation-related modulation of performance differed across tasks (Task $\times$ Rotation interaction), indicating that mental rotation in MI engaged additional resources as compared to VI. (C) Posture test. The left forearm was either parallel (left picture) or perpendicular (right picture) to the right arm. Reaction times (mean \pm SEM) increased as a function of rotation during MI (gray triangles and blocks) and VI (black triangles and blocks). Solving mental rotations with the left hand perpendicular to the right hand facilitated performance during the MI task (gray triangles), but had no effect on performance of the VI task (black triangles). (D) EMG test. Average normalized EMG variability (mean \pm SEM) across hands (left, right), epochs (stimulus, response), and tasks (MI, gray triangles; VI, black diamonds). MI and VI symbols have been offset for display purposes. EMG variance increased only in the right hand, only during the response period, and equally so during both tasks. the same anatomical region as the extrastriate body area (Downing, Jiang, Shuman, \& Kanwisher, 2001). Note that both areas were largely unaffected by rotation.

\section{Rotation-related Activity (MIp, VIp): \\ Anatomical Location}

Cerebral regions showing an increase of activity with increasing rotation are listed in Table 2 . We labeled these
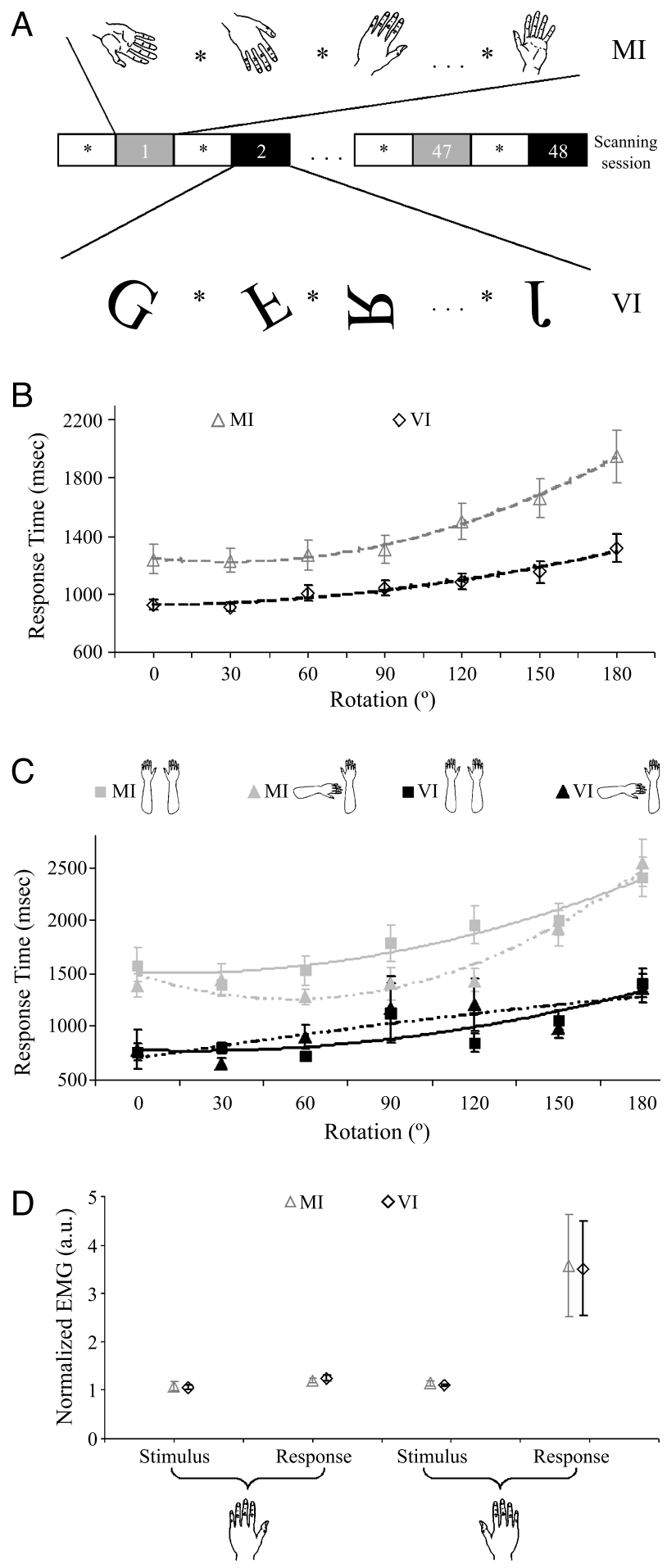


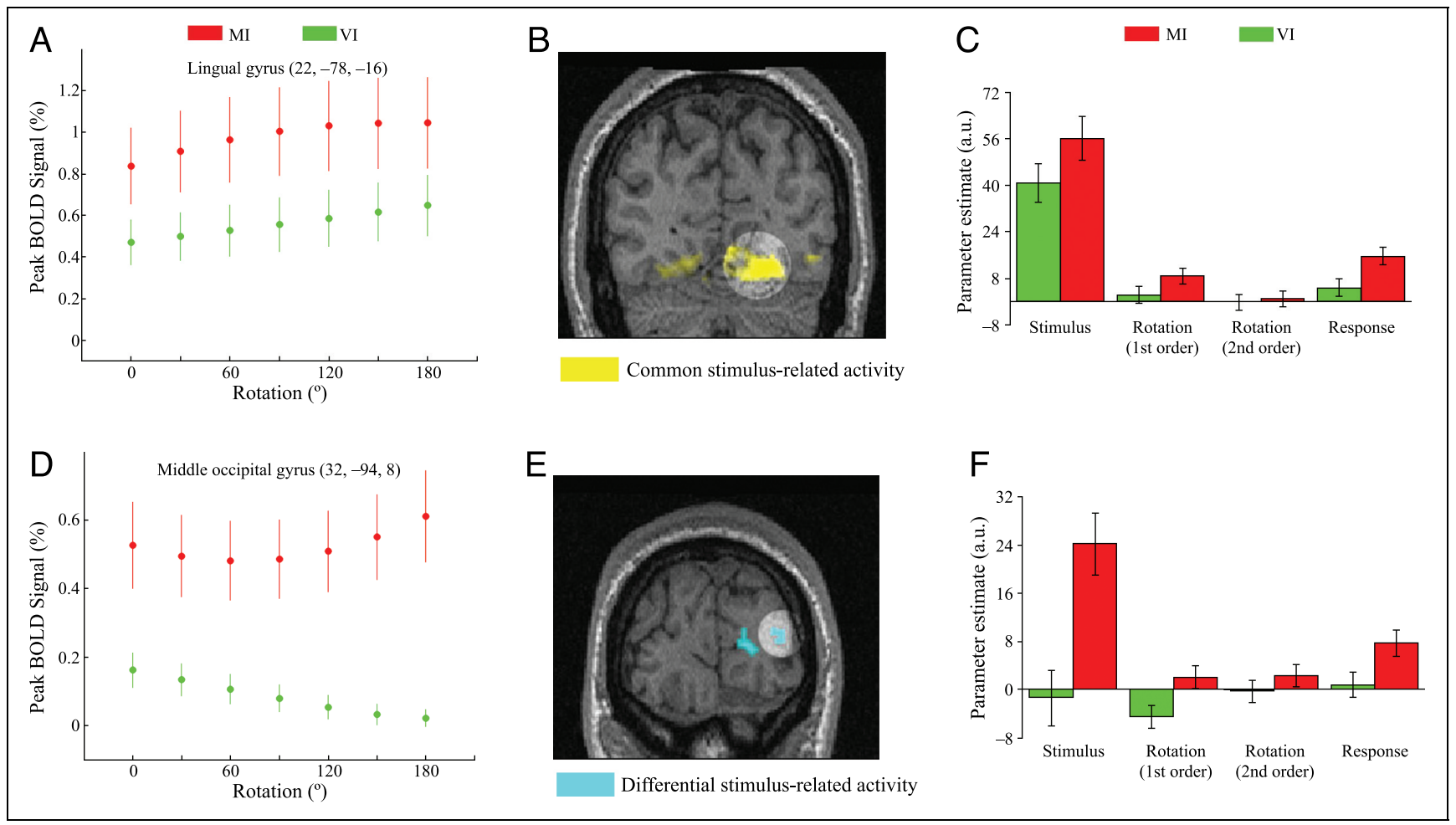

Figure 2. Imaging results—stimulus-related activity. Neural activity as a function of rotation (left column), anatomical localization (middle column), and parameter estimates (right column) of common (upper row) and differential (lower row) stimulus-related activities. The imaging results were corrected for search volume $(p<.01)$. Between-subjects consistency of the results was ensured by means of intersubjects conjuction analyses (Friston, Holmes, Price, et al., 1999). Left column: Peak BOLD signal change (mean adjusted group data \pm SEM) as a function of stimulus rotation (in degrees) for the motor imagery task (MI, in red) and the visual imagery task (VI, in green). Middle column: Images show SPM $\{t\} \mathrm{S}$ (thresholded at $p<.05$ corrected for search volume) superimposed on normalized anatomical coronal sections of one of the subjects.

High-luminance circles show the anatomical location of significant voxels. Clusters of activity shared by both tasks are colored yellow, clusters of differential activity between tasks are colored cyan. Right column: Histograms show parameter estimates ( $\pm S E M$, in arbitrary units) from the same voxels for different model components (stimulus, rotation, and response-see Methods) and imagery types (VI, MI). (A-C) Activation profile, anatomical location (at $y=-78$ ), and parameter estimates of the right lingual gyrus $(22,-78,-16)$, showing common stimulus-related activity (MIs $\cap$ VIs). (D-F) Activation profile, anatomical location (at $y=-94$ ), and parameter estimates of the right middle occipital gyrus $(32,-94,8)$, showing differential stimulus-related activity.

"parametric" increases in neural activity as a function of rotation MI $p$ for MI and VI $p$ for VI.

Again, we distinguished between regions that were commonly modulated during MI and VI (MI $p \cap \operatorname{VI} p)$ and regions showing specific Task $\times$ Rotation interactions $(\mathrm{MI} p>\mathrm{VI} p)$.

Common rotation-related activity across MI and VI tasks (MI $\cap \cap \mathrm{VI} p$ ) was present on the left occipitotemporal fissure (Figure $3 \mathrm{~A}-\mathrm{C}$ ), bilaterally along the ventral portion of the intraparietal sulci (Figure 3D-F), precentral gyri (Figure 3G-I), left frontal operculum, and anterior cingulate sulcus. At lower statistical threshold $(p<.05$ corrected), there were responses along the cerebellum $(-34,-60,-30)$ and the caudate nucleus $(14,0,14)$.

A steeper rotation-related increase of activity during MI than during VI (MI $p>$ VI $p$ ) was found along the right occipito-parietal fissure, the dorsal intraparietal sulcus

Figure 3. Imaging results—rotation-related activity. Neural activity as a function of rotation (left column), anatomical localization (middle column), and parameter estimates (right column) of common and differential rotation-related activities. Left column: Peak BOLD signal change ( \pm SEM) as a function of rotation from significant voxels identified by the contrast MI $p \cap$ VI $p$ (common rotation-related activity) or MI $p>$ VI $p$ (differential rotation-related activity). Middle column: $\operatorname{SPM}\{t\}$ superimposed on anatomical sections. High-luminance circles show the anatomical location of significant areas of common activity (in yellow) or differential activity (in cyan). Right column: Parameter estimates from the same significant voxels. Other conventions as in Figure 2. (A-C) Activation profile, anatomical location (at $y=-68$ ), and parameter estimates of the right temporo-occipital fissure $(-46,-68,-6)$. (D-F) Activation profile, anatomical location (at $y=-36$ ), and parameter estimates of the left ventral intraparietal sulcus $(-42,-36,44)$. (G-I) Activation profile, anatomical location (at $z=+48)$, and parameter estimates of the left precentral gyrus $(-22,-12$, 48). $(\mathrm{J}-\mathrm{N})$ Activation profile, anatomical location (at $z=+60$ ), and parameter estimates of the left precentral sulcus $(-24,2,66$, top circle). (M-N) Activation profile and parameter estimates of the left dorsal intraparietal sulcus $(-26,-60,58$, bottom circle). 


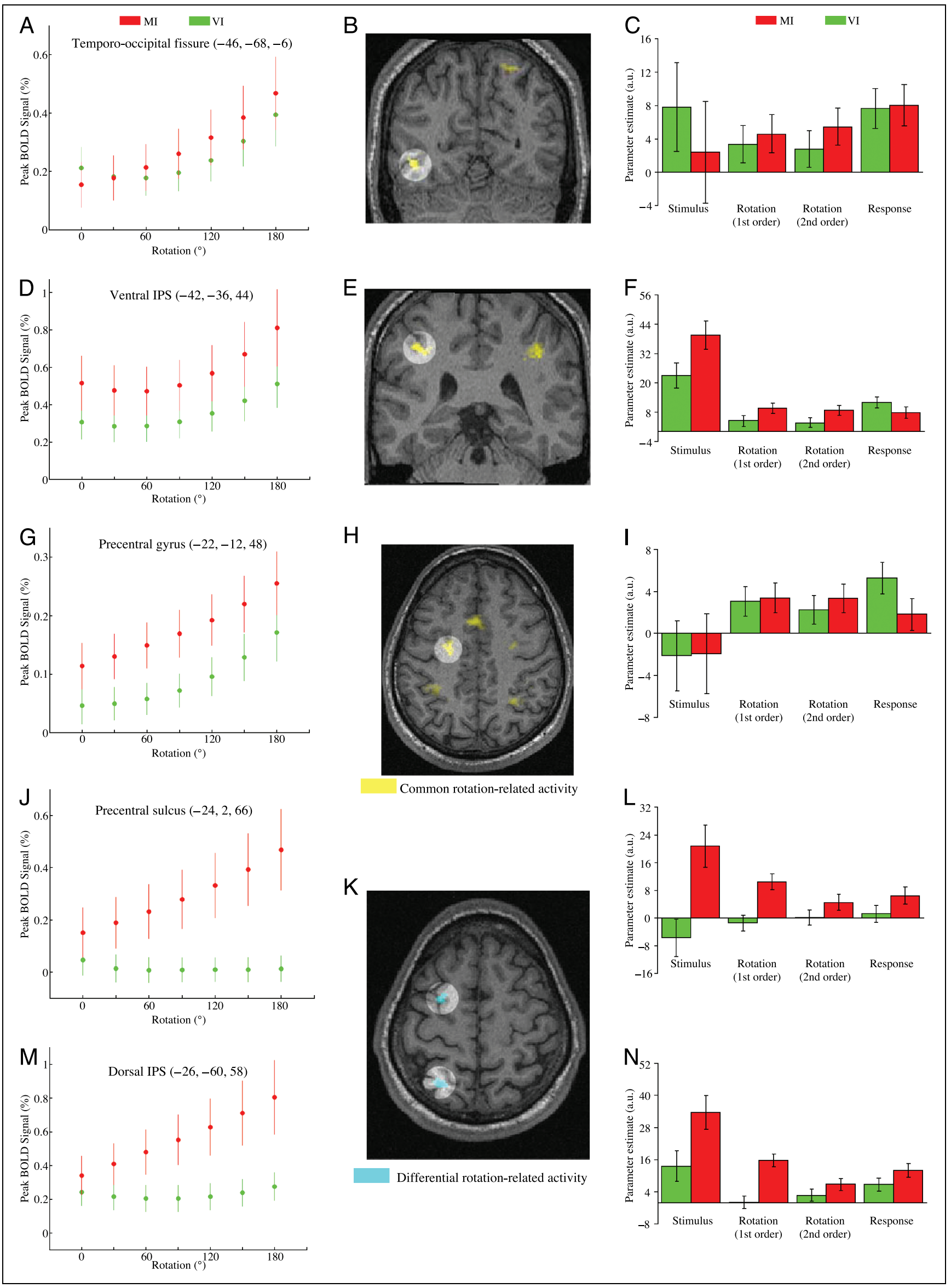


Table 1. Common (MIs $\cap$ VIs) and Differential (MIs $>$ VIs) Stimulus-related Activities

\begin{tabular}{|c|c|c|c|c|c|c|}
\hline \multirow{2}{*}{$\frac{\text { Contrast }}{\mathrm{MIs} \cap \mathrm{VIs}}$} & \multirow{2}{*}{$\begin{array}{l}\text { Anatomical Region } \\
\text { Lingual gyrus }\end{array}$} & \multirow{2}{*}{$\frac{\text { Hemisphere }}{\mathrm{L}}$} & \multirow{2}{*}{$\frac{Z \text { Score }}{6.04}$} & \multicolumn{3}{|c|}{ Stereotactic Coordinates } \\
\hline & & & & -12 & -82 & -14 \\
\hline & & $\mathrm{R}$ & $>8$ & 22 & -78 & -16 \\
\hline & \multirow[t]{2}{*}{ Inferior occipital gyrus } & $\mathrm{L}$ & 4.38 & -38 & -84 & -16 \\
\hline & & $\mathrm{R}$ & 5.88 & 42 & -78 & -12 \\
\hline & Intra-occipital sulcus & $\mathrm{R}$ & 6.39 & 24 & -94 & 16 \\
\hline & Fusiform gyrus & $\mathrm{R}$ & 6.34 & 32 & -52 & -24 \\
\hline & Postcentral sulcus & $\mathrm{L}$ & 6.59 & -44 & -38 & 52 \\
\hline & Frontal operculum & $\mathrm{L}$ & 4.22 & -38 & 14 & 6 \\
\hline & \multirow[t]{2}{*}{ Anterior cingulate sulcus } & $\mathrm{L}$ & 4.04 & -2 & 14 & 48 \\
\hline & & $\mathrm{R}$ & 4.48 & 4 & 16 & 46 \\
\hline & \multirow[t]{2}{*}{ Hippocampus (tail) } & $\mathrm{L}$ & 3.90 & -28 & -40 & 0 \\
\hline & & $\mathrm{R}$ & 4.85 & 22 & -40 & 4 \\
\hline & \multirow[t]{2}{*}{ Cerebellum (culmen) } & $\mathrm{L}$ & 4.16 & -4 & -54 & -10 \\
\hline & & $\mathrm{R}$ & 6.18 & 18 & -50 & -22 \\
\hline & Cerebellum (declive) & $\mathrm{L}$ & 4.87 & -6 & -76 & -22 \\
\hline & Cerebellum (centralis) & $\mathrm{R}$ & 4.29 & 8 & -42 & -28 \\
\hline \multirow[t]{2}{*}{ MIs $>$ VIs } & Calcarine sulcus & $\mathrm{R}$ & 5.39 & 18 & -94 & 2 \\
\hline & Middle occipital gyrus & $\mathrm{R}$ & 5.13 & 32 & -94 & 8 \\
\hline
\end{tabular}

(IPS; Figure $3 \mathrm{M}-\mathrm{N}$ ), the left superior precentral sulcus (Figure 3J-L), the right inferior precentral sulcus, the right anterior cingulate sulcus, and the right middle frontal sulcus. At lower statistical threshold $(p<.05$ corrected), there were responses along the cerebellar vermis $(4,-62,-32)$. There was no stronger rotationrelated activity during VI than MI (VIs > MIs).

The common rotation-related activity (MI $\cap \cap \mathrm{VI} p$ ) found along the occipito-temporal fissure (Figure 3A-C) is near $(<9 \mathrm{~mm}) \mathrm{hMT}+/ \mathrm{V} 5$, the human visual motion complex (Amedi, Jacobson, Hendler, Malach, \& Zohary, 2002), and close $(<7 \mathrm{~mm})$ to a cortical field that selectively responds to circular flow motion (Morrone et al., 2000). Our occipito-temporal cluster is distant (> $12 \mathrm{~mm}$ ) from regions involved in ocular pursuit (Dukelow et al., 2001; Petit \& Haxby, 1999). Our occipito-temporal cluster is also distant (> $28 \mathrm{~mm}$ ) from superior temporal regions involved in performance of "delayed" responses, either in the context of arbitrary visuomotor associations (Toni, Shah, et al., 2002; Toni, Thoenissen, et al., 2001) or in the context of imitative behavior (Decety, Chaminade, Greze, \& Meltzoff, 2002; Iacoboni et al., 2001). Furthermore, the present dataset showed no significant $(p<.05)$ rotationrelated signals on volumes of interest (VOIs) centered on the local maxima reported in those studies (Decety et al., 2002; Toni, Shah, et al., 2002; Iacoboni et al., 2001; Toni,
Thoenissen, et al., 2001). The common rotation-related activity (MI $p \cap \operatorname{VI} p$ ) found bilaterally along the "ventral" portion of the intraparietal sulci $(36,-40,38 ;-42,-36$, $44)$ is within variability range of the human ventral intraparietal area (VIP; Bremmer et al., 2001). The common rotation-related activity found bilaterally along the "lateral" portion of the intraparietal sulci $(24,-60,54 ;-30$, $-50,54)$ falls within the variability range of the human parietal eye fields (Berman et al., 1999). The common rotation-related activity found bilaterally along the superior precentral gyri $(28,-8,48 ;-22,-12$, 48; see Figure 3) falls within the variability range of the human frontal eye fields (Berman et al., 1999).

The differential rotation-related activity $(\mathrm{MI} p>\mathrm{VI} p)$ found in the parietal (Figure $3 \mathrm{M}-\mathrm{N}$ ) and precentral cortex (Figure 3J-L) fall "outside" the variability range of the parietal and frontal eye fields (Berman et al., 1999). The differential rotation-related activity (MI $p>\mathrm{VI} p)$ observed in the right inferior precentral sulcus is near $(<10 \mathrm{~mm})$ a human precentral field involved in polymodal motion processing (Bremmer et al., 2001). The differential rotation-related activity (MI $p>$ VI $p$ ) found on the right middle frontal sulcus is within cytoarchitectonic-defined area 9/46 (Rajkowska \& Goldman-Rakic, 1995), in a region involved in response selection (Rowe, Toni, Josephs, Frackowiak, \& Passingham, 2000), but distant $(>19 \mathrm{~mm})$ from a right prefrontal region in- 
Table 2. Common (MI $p \cap \operatorname{VI} p)$ and Differential (MI $p>\operatorname{VI} p)$ Rotation-related Activities

\begin{tabular}{|c|c|c|c|c|c|c|}
\hline \multirow{2}{*}{$\frac{\text { Contrast }}{\operatorname{MI} p \cap \operatorname{VI} p}$} & \multirow{2}{*}{$\begin{array}{c}\text { Anatomical Region } \\
\text { Temporo-occipital fissure }\end{array}$} & \multirow{2}{*}{$\frac{\text { Hemisphere }}{\mathrm{L}}$} & \multirow{2}{*}{$\frac{Z \text { Score }}{4.80}$} & \multicolumn{3}{|c|}{ Stereotactic Coordinates } \\
\hline & & & & -46 & -68 & -6 \\
\hline & Caudal intraparietal sulcus & $\mathrm{R}$ & 4.53 & 34 & -74 & 30 \\
\hline & Ventral intraparietal sulcus & $\mathrm{L}$ & 5.10 & -42 & -36 & 44 \\
\hline & & $\mathrm{R}$ & 5.80 & 36 & -40 & 38 \\
\hline & Dorsal intraparietal sulcus & $\mathrm{L}$ & 4.26 & -30 & -50 & 54 \\
\hline & & $\mathrm{R}$ & 4.61 & 24 & -60 & 54 \\
\hline & Superior precentral gyrus & $\mathrm{L}$ & 5.02 & -22 & -12 & 48 \\
\hline & & $\mathrm{R}$ & 4.57 & 28 & -8 & 48 \\
\hline & Anterior cingulate sulcus & $\mathrm{L}$ & 5.21 & 0 & 14 & 50 \\
\hline & Frontal operculum & $\mathrm{L}$ & 5.43 & -28 & 22 & 0 \\
\hline \multirow[t]{7}{*}{$\mathrm{MI} p>\mathrm{VI} p$} & Occipito-parietal fissure & $\mathrm{R}$ & 4.93 & 26 & -66 & 40 \\
\hline & Dorsal intraparietal sulcus & $\mathrm{L}$ & 5.68 & -26 & -60 & 58 \\
\hline & & $\mathrm{R}$ & 5.09 & 26 & -56 & 56 \\
\hline & Inferior precentral sulcus & $\mathrm{R}$ & 4.75 & 46 & 4 & 26 \\
\hline & Superior precentral sulcus & $\mathrm{L}$ & 4.36 & -24 & 2 & 66 \\
\hline & Anterior cingulate sulcus & $\mathrm{R}$ & 4.40 & 6 & 20 & 44 \\
\hline & Middle frontal sulcus & $\mathrm{R}$ & 4.76 & 34 & 44 & 38 \\
\hline
\end{tabular}

volved in inhibitory control (Garavan, Ross, \& Stein, 1999; Konishi et al., 1999).

\section{Rotation-related Activity (MIP, VIp): Hemodynamic Response}

Figure 3A-C illustrates the strong increase in activity in occipito-temporal cortex with increasing stimulus rotation (despite the absence of any physical or illusory motion of the visual stimuli). Figure 3G-I illustrates the response modulation of the putative left frontal eye field. It can be seen that the activity of this precentral cluster increases with increasing rotation equally during both VI and MI tasks.

Figure $3 \mathrm{~J}-\mathrm{N}$ illustrates the responses evoked in portions of the left parietal and premotor cortex, showing differential rotation-related activity. During MI, both clusters show a strong response. There are also significant modulations of BOLD signal as a function of rotation, whereas there is no modulation of rotation during VI. In contrast to the comparable activity profiles evoked by MI, these two cortical regions showed differential responses during the VI task. The parietal cluster responded to the visual stimuli presented during VI. Conversely, the precentral cluster was silent during VI.

We performed a further analysis on these two regions specifically involved in $\mathrm{MI}$, to test whether there is a direct relationship between behavioral and neural changes as a function of rotation. We exploited the fact that different subjects of our group showed differences in the speed of mental rotation, as parameterized by (linear and quadratic) increases in RTs as a function of rotation. Figure 4 shows that subject-by-subject variance in the behavioral rotation-related effects was positively and significantly correlated with the neural rotationrelated effects during MI (posterior parietal cortex: $r=$ $.567, p=.027$; precentral cortex: $r=.550, p=.032$ ), but not during VI (posterior parietal cortex: $r=.049$, $p=.440$; precentral cortex: $r=-.200, p=.266$ ).

\section{Response-related Activity (MIr, VIr): Anatomical Location}

Table 3 lists those cerebral regions with activity modulated by residual trial-by-trial variability in RT (i.e., orthogonal to the rotation-related modulation of RTs). Regions that were equally modulated during performance of either task (MI $r \cap \mathrm{VI} r$ ) included the middle occipital gyri, the right intraoccipital sulcus, the left postcentral gyrus, the left inferior and superior precentral gyri, and the right anterior cingulate sulcus. There was no significant differential activity for the comparisons $\mathrm{MI} r>\mathrm{VI} r$ or $\mathrm{VI} r>\mathrm{MI} r$. The response-related activity found along the caudal and rostral banks of the 


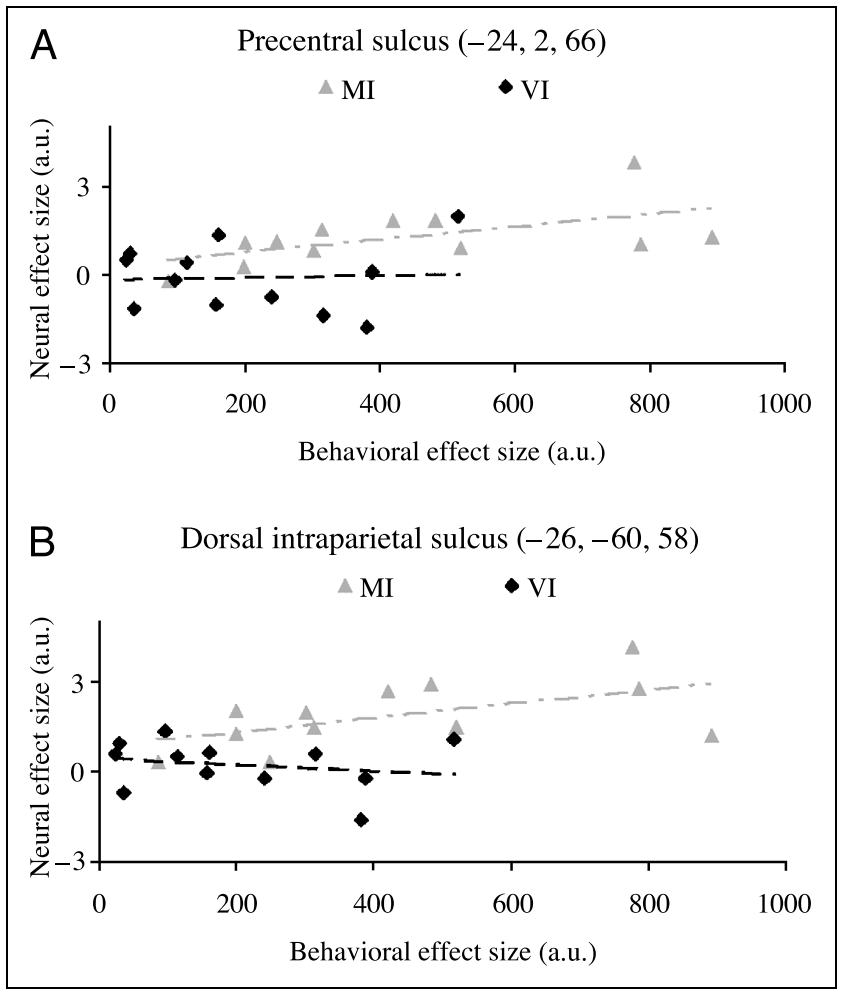

Figure 4. Imaging results-relationship between behavioral and neural effects. Effect size of linear and quadratic increases in neural activity (neural effect size, in arbitrary units) across subjects as a function of linear and quadratic effect size of rotation on reaction time (behavioral effect size, in arbitrary units) during MI (gray triangles) and VI (black diamonds). Subject-by-subject variance in the behavioral rotation-related effects was positively and significantly correlated with the neural rotation-related effects during MI, but not during VI in the outlined regions. (A) Precentral sulcus $(-24,2$, 66; see Figure $3 \mathrm{~K}$, top circle). (B) Dorsal intraparietal sulcus $(-26,-60,58$; see Figure $3 \mathrm{~K}$, bottom circle).

central sulcus corresponds to the morphologically and metabolically defined location of the hand area in the primary motor cortex (Maldjian, Gottschalk, Patel, Detre, \& Alsop, 1999).
Response-related Activity (MIr, VIr): Evoked

\section{Hemodynamic Responses}

The BOLD signal of pre- and postcentral clusters is not modulated by rotation, or differentially affected by task. Rather, it displays equal activity across rotation levels during both MI and VI. These regions show no first- or second-order rotation-related effects in either of the two tasks, and overlapping effects of task.

\section{DISCUSSION}

In this study, we have used implicit MI as at tool to investigate neural activity related to planning hand movements, yet independent from sensory or motoric events. In the following sections, we discuss our behavioral and neural findings, focusing on fronto-parietal responses and their interactions with occipito-temporal activity. We conclude by elaborating on the relevance of these findings for current models of action planning (Blakemore, Wolpert, \& Frith, 2002; Hommel, Musseler, Aschersleben, \& Prinz, 2001; Milner \& Dijkerman, 2001).

\section{Behavioral Performance}

We have used a mental rotation paradigm to induce MI and VI (Kosslyn, 1996). The tasks were performed with low ERs, indicating that the subjects were effectively engaged in the imagery tests. The RT profiles changed as a function of rotation (Figure 1B), indicating that the subjects used mental rotation to judge the laterality of hands (MI task) and letters (VI task). The rotationrelated modulation of performance differed across tasks, indicating that mental rotation in MI engaged additional resources as compared to VI. Subjects' posture influenced the RT profile during the MI task, but not during the VI task (Figure 1C), in line with the results of a previous study (Parsons, 1994) and suggestive of the fact that sensorimotor structures support mental rotation of

Table 3. Common (MIr $\cap \mathrm{VI} r)$ Response-related Activities

\begin{tabular}{llccccr}
\hline Contrast & \multicolumn{1}{c}{ Anatomical Region } & Hemisphere & Z Score & & Stereotactic Coordinates \\
\hline $\mathrm{MI} r \cap \mathrm{VI} r$ & Intra-occipital sulcus & $\mathrm{R}$ & 4.95 & 22 & -88 & 18 \\
& Middle occipital gyrus & $\mathrm{L}$ & 4.96 & -38 & -78 & -6 \\
& & $\mathrm{R}$ & 5.28 & 36 & -76 & 22 \\
& Postcentral gyrus & $\mathrm{L}$ & 5.70 & -46 & -24 & 60 \\
& Central sulcus & $\mathrm{L}$ & 4.36 & -38 & -24 & 62 \\
& Inferior precentral sulcus & $\mathrm{L}$ & 4.53 & -54 & 4 & 34 \\
& Superior precentral sulcus & $\mathrm{L}$ & 4.79 & -30 & -6 & 68 \\
& Anterior cingulate sulcus & $\mathrm{R}$ & 4.81 & 6 & 12 & 52 \\
\hline
\end{tabular}


hands, but not of letters. EMG recordings indicated that, apart from the required button press, subjects did not move their fingers or rotate their hands during task performance (Figure 1D). In summary, the MI task was solved independently from overt movements and it required additional cognitive "motor" processes over and above general imagery-related processes. The disproportionately longer RTs observed at larger rotations requiring physically awkward arm postures and the taskspecific modulation of RT profiles as a function of arm posture indicate that biomechanical constraints played a significant role in the performance of the MI task. On the basis of this behavioral evidence, and considering that we did not instruct or train subjects to engage in MI or VI, we can interpret rotation-related "neural" activity that differed across tasks as reflecting motor cognitive processes, rather than task-related differences in strategic control, selective attention, or working memory.

\section{Task Complexity}

In light of the RT differences between MI and VI, one could ask whether the activation differences found are due to the recruitment of movement-specific representations or just the greater work required by the MI task. Although absence of behavioral differences as well as behavioral corroboration seems to posit potential pitfalls for inference of neural activation data (Wilkinson \& Halligan, 2004), we sought to tackle this potential confound by inspecting subject-by-subject variability in behavioral and neural effects across tasks. We argued that, provided there is a sizable overlap in the behavioral rotation-related effects evoked in individual subjects during MI and VI, the regions that we claimed to be specifically involved in movement representations should show a correlation between behavioral and neural effects across subjects during MI, whereas the correlation between behavior and neural responsivity should be absent during VI. Figure 4 shows the application of this rationale in two areas showing differential rotationrelated modulation of neural activity. The functional relevance of these regions will be discussed below.

\section{Posterior Parietal Cortex}

In line with previous reports (Wolbers, Weiller, \& Büchel, 2003; Richter, Somorjai, et al., 2000; Cohen et al., 1996), we found large portions of the IPS to be involved in mental rotation (Tables 2 and 3). By manipulating type and load of imagery, we could highlight a dorsoventral gradient of activity along the IPS. The ventral IPS clusters showed similar rotation-modulated responses during both MI and VI (Figure 3D-F). Anatomically, these clusters fall close to the human equivalents of the VIP (Bremmer et al., 2001) and the lateral intraparietal area (LIP; Berman et al., 1999). Functionally, the response profiles of the ventral IPS clusters are compatible with the properties of the macaque's VIP and LIP, namely, VIP's sensitivity to circular optic flows (Schaafsma \& Duysens, 1996) and LIP's involvement in saccadic eye movements (Barash, Bracewell, Fogassi, Gnadt, \& Andersen, 1991). Similar rotation-modulated effects were also found in the occipito-temporal cortex (hMT+/V5; Figure $3 \mathrm{~A}-\mathrm{C}$ ) and frontal regions (hFEF; Figure 3G-I). In the macaque, these cortical areas are connected to the VIP-LIP (Boussaoud, Ungerleider, \& Desimone, 1990).

Conversely, the dorsal IPS clusters showed rotationmodulated responses during MI but not during VI (Figure $3 \mathrm{M}-\mathrm{N}$ ). Anatomically, the position of these clusters along the human IPS is consistent with the location of the medial intraparietal area (MIP) along the IPS in the macaque (Colby, Gattass, Olson, \& Gross, 1988). Functionally, the response profiles of the dorsal IPS clusters are compatible with the properties of the macaque's MIP, namely, arm- and hand-centered visuoproprioceptive receptive fields (Colby, 1998). Finally, MIdependent rotation-modulated effects were found not only along the dorsal IPS, but also in the dorsolateral premotor cortex (Figure 3J-L) and in occipito-parietal regions (Table 2). In the macaque, these cortical areas are directly connected to the MIP (Matelli, Govoni, Galletti, Kutz, \& Luppino, 1998).

These results localize and detail cognitive motor processes, over and above generic imagery-related phenomena. Examples of the latter are eye movements, known to constitute an essential component of imagery tasks (Laeng \& Teodorescu, 2002). The functional and anatomical characteristics of the ventral IPS signal (Figure 3D-F) are compatible with a role in controlling rotation-related eye movements common to both imagery tasks. Conversely, the dorsal IPS activity (Figure 3M$\mathrm{N})$ cannot be related to eye movements, being indifferent to stimuli rotation in VI but not in MI. It might be argued that the absence of rotation-related modulation of neural responses during VI in the dorsal IPS is a floor effect due to different task difficulties between MI and VI. However, nearby regions, such as the ventral IPS clusters, show a strong rotation-related modulation of neural activity during VI (Figure 3D-F). Furthermore, although different subjects of our group experienced different levels of difficulty during task performance (as parameterized by the increase in RTs as a function of rotation), this dorsal parietal region revealed a significant and positive correlation between behavioral and neural rotation-related effects during MI, but not during VI (Figure 4A).

Having excluded these alternative interpretations, it is conceivable to link this dorsal parietal response with specific MI-related neural processes, namely, the integration of limb-related visual and somatosensory information. It has been shown how the superior parietal lobule combines these sensory inputs for coding static arm position (Graziano, Cooke, \& Taylor, 2000). Here, 
we extend the scope of those findings to "dynamic" motor cognitive processes, localizing the effect to the dorsal portion of the middle third of the human IPS.

\section{Frontal Cortex}

There has been mixed evidence concerning the involvement of the premotor and motor cortex in imagery tasks (Gerardin et al., 2000; Richter, Somorjai, et al., 2000; Carpenter, Just, Keller, Eddy, \& Thulborn, 1999; Bonda, Petrides, Frey, \& Evans, 1995). By disambiguating imagery-related signals from activity associated with residual variability in response times, here we could functionally differentiate between prefrontal, central, and precentral activities. Neural activity at the junction between the superior frontal sulcus and the superior precentral gyrus (putative hFEF; Berman et al., 1999; Paus, 1996) were equally modulated by rotation in both MI and VI (Figure 3G-I). The response profile and the location of these frontal clusters are compatible with control of eye movements, rather than planning of hand movements. Conversely, the rotation-modulated precentral activity occurring during MI (Figure 3J-L) cannot be related to eye movements or visuomotor processes. It can be argued that the relative ease of VI (as parameterized by the increase in RTs as a function of rotation) might have failed to evoke significant neural responses in this region. However, although the behavioral speed of rotation observed during VI is half the speed observed during MI (Figure 1B), the rotation-related modulation of dorsal precentral activity is null during VI but robust during MI (Figure 3J). Furthermore, despite the sizeable overlap in the behavioral rotation-related effects evoked in individual subjects during MI and VI, this precentral region revealed a significant and positive correlation between behavioral and neural rotationrelated effects during MI, but not during VI (Figure 4B). Therefore, it is likely that that the precentral response is specifically related to the generation of "motor plans." Electrical stimulation of the macaque's precentral gyrus can evoke complex upper-limb movements (Graziano, Taylor, \& Moore, 2002). Here we confirm and extend those findings by having stimulated human precentral neurons through imagined movements rather than electrical currents.

Neural activity around the knob of the central sulcus (hand region of M1 and S1; Maldjian et al., 1999; SastreJaner et al., 1998) was significantly correlated with the actual motor responses, but it neither showed any relationship with stimulus rotation, nor did it distinguish between MI and VI. This result indicates that, at the mesoscopic level of analysis of fMRI, the putative primary motor cortex deals with movement execution, rather than motor planning. However, it remains to be seen whether this finding is limited to the current experimental setup, or whether it represents a general modus operandi of the human primary motor cortex.
Neural activity in the right inferior precentral sulcus increased as a function of rotation during MI, but not during VI. This response profile is compatible with the functional and anatomical characteristics of the macaque's premotor neurons clustered in front of the spur of the arcuate sulcus, namely, arm-centered, motionsensitive visuotactile receptive fields (Graziano \& Gandhi, 2000; Graziano, Hu, \& Gross, 1997; Fogassi et al., 1996). Similar properties have emerged from the human inferior precentral cortex (Bremmer et al., 2001) in a location close $(<10 \mathrm{~mm})$ to the present cluster. Our findings suggest that this region might not be concerned with processing sensory stimuli per se, but rather with evaluating their relevance for preparing an adequate motor response.

Neural activity along the right middle frontal sulcus (putative human 46/9; Rajkowska \& Goldman-Rakic, 1995) revealed MI-dependent increases in neural activity with increasing rotation. It has been argued that MI requires inhibition of overt movement (Jeannerod, 1995), and the right prefrontal cortex has been implicated in inhibitory control (Garavan et al., 1999; Konishi et al., 1999). However, those responses are distant (> $19 \mathrm{~mm}$ ) from our site. Rather, the activity found in this area (46/9) is compatible with the role of this region in selecting between competing responses (Hadland et al., 2001; Rowe et al., 2000), that is, selection of the appropriate hand and corresponding covert movement during the MI task.

\section{Occipito-Temporal Cortex}

Previous studies have shown that extrastriate activity correlates with subjects' perceptual experience, independently from the characteristics of the sensory inputs (Nichols \& Newsome, 2002; Tootell et al., 1995). By manipulating the amount of mental rotation while keeping the actual stimuli stationary, here we could isolate extrastriate signals independently from physical or perceived rotations of the visual stimuli. Neural activity around the occipito-temporal fissure (putative hMT+/V5; Amedi et al., 2002) showed overlapping rotation-modulated signals during both imagery tasks (Figure $3 \mathrm{~A}-\mathrm{C}$ ). Incidentally, this result provides support to "depictive" accounts of VI (Kosslyn, 1996) by showing that mental rotation of "stationary" visual stimuli modulates neural activity in the cortex sensitive to rotational optical flow (Morrone et al., 2000; Graziano, Andersen, \& Snowden, 1994). By the same token, our findings beg the question of whether and how such extrastriate activity contributes to the manipulation of action representations.

Functional interactions between movement- and perceptual-related structures have been postulated by computational and cognitive models of motor control as a way to predict the sensory consequences of a planned movement (Hommel et al., 2001; Wolpert \& Ghahrama- 
ni, 2000). Here we localize these perceptuo-motor interactions to frontal and occipito-temporal regions, which are both part of the "dorsal" visuomotor stream (Milner \& Goodale, 1995). In this context, it can be noticed that the extrastriate activity reported in this experiment (Figure 3B) is spatially distinct from the posterior temporal responses reported in studies dealing with delayed responses, either in the context of arbitrary visuomotor associations (Toni, Shah, et al., 2002; Toni, Thoenissen, et al., 2001) or in the context of imitative behavior (Decety et al., 2002; Iacoboni et al., 2001). Accordingly, our findings provide further support for the hypothesis that delayed actions and immediate responses rely on different neural circuits (Rossetti \& Pisella, 2002; Milner \& Dijkerman, 2001).

\section{Conclusions}

We have characterized topography and content of neural correlates of action planning, and dissociated them from neural responses to external events by virtue of an implicit MI task. We have confirmed that posterior parietal and precentral regions are involved in specifying intended actions (Toni, Thoenissen, et al., 2001; Snyder, Batista, \& Andersen, 1997; Kalaska \& Crammond, 1995). We have provided novel evidence supporting the notion that while the superior parietal lobule combines somatosensory and visual information, the dorsal precentral gyrus generates motor plans, and the primary motor cortex deals with movement execution.

\section{METHODS}

Six healthy, young ( $25 \pm 2$ years) men participated in the study after giving written informed consent according to institutional guidelines of the local ethics committee (CMO region Arnhem-Nijmegen, Netherlands). All participants were right-handed (Edinburgh Handedness Inventory, Oldfield, 1971; $90 \pm 10 \%$, mean \pm SD).

\section{Tasks}

We used two tasks, an MI and a VI task. Four line drawings of hands (left or right hand, viewed either from the back or from the palm) served as stimuli for the MI task. Four typographical characters (F, G, J, and R, in Times New Roman font) served as stimuli for the VI task. Each of these eight stimuli was rotated around the vertical axis of the picture to generate mirror images. Further clockwise rotations in the plane of the picture [from an upright position $\left(0^{\circ}\right)$ until a rotation of $180^{\circ}$ in six steps of $30^{\circ}$ ] generated two sets of 56 stimuli each (Figure 1A). These stimuli were serially presented to the subjects in a random order. During the MI task, the subjects had to report whether the displayed hand drawing was a left hand or a right hand, regardless of the angle of rotation of each stimulus from its upright position (in short, rotation). During the VI task, the subjects had to report whether the displayed typographical character was a canonical letter or its mirror image, regardless of its rotation. In both tasks, the subjects responded by pressing either the left or right button with the index or the middle finger of their right hand.

\section{Experimental Time Course}

The main experiment consisted of a training session followed by a scanning test. During the training session, the subjects were first shown the task instructions and then performed the MI and VI tasks in 20 alternating blocks of 7 trials. Each trial started with the presentation of a fixation cross for a variable interval $(0.75-1.25 \mathrm{sec})$, followed by a visual stimulus (i.e., a typographical character or a drawing of a hand). When a behavioral response was provided, the visual stimulus was replaced by the fixation cross. The intertrial interval (ITI) was adjusted to task performance, in order to balance the time spent off-task across experimental conditions (off-task time designates the temporal intervals interposed between a behavioral response and the next stimulus presentation). Pilot data showed that solving the MI task took longer than solving the VI task. As expected, time on-task also changed as a function of rotation, with longer RTs for larger rotations. Accordingly, the use of a fixed ITI would have caused off-task time to become a function of both task and rotation. Note that although our analysis does not rely on direct contrasts between imagery and baseline epochs, the presence of a correlation between off-task time and the experimental factors might have contaminated task- and rotation-related effects with neural phenomena occurring during the off-task time. To avoid this confound (McKiernan, Kaufman, KuceraThompson, \& Binder, 2003; Binder et al., 1999), we adjusted the ITI according to the formula: ITI $=C+$ $\alpha / \pi$, where $C=2.0 \mathrm{sec}$ (VI) or $2.5 \mathrm{sec}(\mathrm{MI}) ; \alpha=$ stimulus rotation ( $\mathrm{rad})$. Stimulus rotation was randomized from trial to trial. At the end of each block, a fixation cross was presented for $5 \mathrm{sec}$ (baseline). A transient change in size of the fixation cross announced the start of the next block of trials.

The subjects were given four further blocks of training in the scanner (28 trials), just before the beginning of the scanning test. This allowed them to become familiar with the experimental setup while lying in the scanner. During the scanning test (336 trials in 48 blocks), the subjects performed the MI and VI tasks as practiced during the training session. In order to avoid collinearity of the regressors describing the main effect of task (see Image Analysis), the duration of each baseline epoch was increased to 20 sec. 


\section{Experimental Setup}

During the training session, the subjects faced the computer screen with both hands on the table (radial side towards the body midline), using the index and middle finger of their right hand to provide responses through a computer mouse. Stimulus presentation and response collection were carried out through a PC running Presentation (www.neurobehavioralsystems.com).

During the scanning test, the subjects lay supine in the scanner. An adjustable padded head holder minimized head movements. Visual stimuli were projected onto a screen at the back of the scanner and seen through a mirror above the subjects' heads. The visual stimuli (white lines on a black background) subtended a visual angle of $\sim 10^{\circ}$. Motor responses (i.e., finger flexions resulting in button presses) were recorded via an MR-compatible keypad (www.mridevices.com), positioned on the right side of the subject's abdomen. Subjects' hands were lying along the longitudinal axis of the body, with their radial side towards the midline. Timing of functional brain images, stimulus presentation, and subjects' response was simultaneously recorded via a PC running Presentation.

On a separate occasion, 3 of the 6 subjects underwent an additional test in the scanner in order to assess skeletomotor activities during task performance (EMG test). Subjects performed the two tasks in the same conditions as described for the scanning test. In addition, bipolar surface EMGs were measured (sampling rate: $5.0 \mathrm{kHz}$ ) from both right and left forearms, in order to assess activity of "both hand and carpal muscles." We used MR-compatible electrodes and amplifiers (bandpass filter $0.50-70 \mathrm{~Hz}$, notch filter $50 \mathrm{~Hz}$ ) in combination with BrainVision software (http://www.brainproducts. com/). During the EMG measurements, the MR gradients were turned off.

Finally, 3 of the 6 subjects participated in a further test outside the scanner in order to assess postural contributions to task performance (posture test). During this test, we used the same setup described for the training session. The crucial experimental manipulation concerned the position of the left hand, being either parallel or perpendicular to the right hand. Subjects performed a total of 10 blocks (consisting of 70 trials for MI and 25 trials for VI). Block order was counterbalanced within subjects.

\section{Image Acquisition}

Functional images were acquired on a Siemens SONATA 1.5 T MRI system equipped with echo-planar imaging (EPI) capabilities, using the standard head coil for radio-frequency transmission and signal reception. BOLD-sensitive functional images were acquired using a single-shot gradient EPI sequence $(\mathrm{TR}=2560 \mathrm{msec}$; $\mathrm{TE}=40 \mathrm{msec} ; 32$ axial slices; slice thickness $=3.5 \mathrm{~mm}$;
FOV $=224 \mathrm{~mm}$ ). High-resolution anatomical images were acquired using an MP-RAGE sequence (TE/TR = $3.93 / 2250 \mathrm{msec}$; voxel size $=1.0 \times 1.0 \times 1.0 \mathrm{~mm} ; 176$ sagittal slices; FOV $=256 \mathrm{~mm}$ ).

\section{Image Analysis}

Image analysis was performed with SPM99 (Statistical Parametric Mapping, www.fil.ion.ucl.ac.uk/spm). Functional images were spatially realigned using a sinc interpolation algorithm that estimates rigid body transformations (translations, rotations) by minimizing head movements between each image and the reference image (Friston, Ashburner, et al., 1995). Subsequently, the time series for each voxel was realigned temporally to acquisition of the middle slice. Images were normalized to a standard EPI template centered in Talairach space (Ashburner \& Friston, 1999) by using 12 linear parameters (translation, rotation, zoom, and shear) and subsampled at an isotropic voxel size of $2 \mathrm{~mm}$. The normalized images were smoothed with an isotropic 10-mm full-widthat-half-maximum (FWHM) gaussian kernel. Anatomical images were spatially coregistered to the mean of the functional images (Ashburner \& Friston, 1997) and spatially normalized by using the same transformation matrix applied to the functional images. The statistical model consisted of independent partitions accounting for different sources of variance on a trial-by-trial basis (i.e., we used an event-related design). We considered a main effect, time-locked to stimulus onset (2 levels: MI, VI) and its modulation by rotation ( 7 levels: $0^{\circ}$ to $180^{\circ}$, in $30^{\circ}$ steps). On the basis of the linear and quadratic trends in the behavioral data (see Results: Task Performance), we modeled neural modulation of rotation with linear and quadratic polynomial expansions. The variability in RTs, orthogonalized to rotation- and stimulusrelated regressors, was also modeled for MI and VI trials. In summary, our model characterized the variance in neural signal along three orthogonal dimensions, namely, the overall stimulus-related effects (stimulusrelated components: MIs, VIs), the effect of mental rotation (parametric modulation of stimulus rotation: MI $p$, $\mathrm{VI} p$ ), and the residual variability explained by trial-bytrial RTs (response-related effects: MI $r$, VI $r$ ). The hemodynamic responses generated by these events were modeled by convolving delta functions time-locked to their occurrence with a standard hemodynamic response function and its first two temporal derivatives (Friston, Holmes, Poline, et al., 1995). This approach ensured a good compromise between statistical sensitivity and model flexibility (i.e., a parsimonious set of basis function that allowed for variations in timing and shape of the hemodynamic responses across voxels and conditions). Each of these regressors was mean-adjusted to remove differences in offset and range-normalized to allow for meaningful comparison of parameter estimates (i.e., regression coefficients in the context of the present 
multiple regression analysis) across conditions. Finally, the statistical model included independent partitions for other sources of variance, namely, error trials, residual head movement-related effects, low-frequency signal drifts over time, and overall differences between subjects.

\section{Statistical Inference}

The statistical significance of the estimated evoked hemodynamic responses was assessed using $t$-statistics in the context of a multiple regression analysis. The null hypothesis was that the variance explained by a given regressor was consistent with the residual error, once the variance explained by the other components of the model was accounted for. Linear compounds (contrasts) were used to determine the effects associated with each task component, generating $t$-values for each voxel in the image, that is, statistical parametric maps of $t$-values $(\mathrm{SPM}\{t\} \mathrm{s})$. In particular, for each of the three orthogonal task dimensions detailed above, we further distinguished between regions showing either common activity (indicated by " $\cap$ ") (Friston, Holmes, Price, Buchel, \& Worsley, 1999) or differential activity (indicated by "> ") across levels of a given experimental factor. This rationale generated the following series of contrasts:

(a) Stimulus-related activity: MIs > VIs; MIs $\cap$ VIs; VIs $>$ MIs.

(b) Rotation-related activity: $\mathrm{MI} p>\operatorname{VI} p$; MI $p \cap \mathrm{VI} p$; VI $p>$ MI $p$.

(c) Response-related activity: MI $r>\mathrm{VI} r$; MI $r \cap \mathrm{VI} r$; VIr $>$ MI $r$.

These contrast images indicate the spatial distribution of significant activity for a given task component. Gaussian field theory allowed us to make inferences corrected for the number of nonindependent comparisons (Friston, Holmes, Worsley, Poline, et al., 1995). The effective degrees of freedom of the error term took into account the temporal autocorrelation of the data (Friston, Holmes, Poline, et al., 1995). We report the results of a fixed-effect group analysis. The inferences we provide are about the presence of an effect in these subjects during these scanning sessions and not about the average size of the effect in the population from which the subjects were drawn (Friston, Holmes, Price, et al., 1999; Friston, Holmes, \& Worsley, 1999). Consistency of the effects across subjects was ensured via multisubject conjunction analyses (Friston, Holmes, Price, et al., 1999). The statistical analysis of the fMRI data adopted a mass univariate approach, and the inferences pertain to the voxel level, with an arbitrarily chosen ER of $1 \%(p$ threshold $=.01 ; Z$ threshold $=3.84)$. This approach introduces a multiple comparisons problem. Here we have corrected for performing multiple tests over the whole brain by using the False Discovery Rate approach (Genovese, Lazar, \& Nichols, 2002).
In addition to the procedure described above, in one particular instance, we have constrained our inferences on the basis of independent anatomical information, using a VOI approach. In this case, we aimed at testing whether the present dataset revealed any significant rotation-related activity in cortical regions previously implicated in supporting movement representations during "delayed" motor responses (Decety et al., 2002; Toni, Shah, et al., 2002; Iacoboni et al., 2001). Accordingly, we relied on published stereotactical coordinates to position VOIs along the superior temporal region, and we used the FWHM of our statistical images to define the radius of the VOIs. Our goal was to exploit the higher sensitivity of VOI-based analyses to exclude that the lack of activity observed in these regions in the present study was not due to a thresholding effect.

Anatomical details of significant signal changes were obtained by superimposing the SPM $\{t\}$ s on the structural images of each subject. The atlases of Schmahmann et al. (1999), Duvernoy, Cabanis, and Vannson (1991), and Ono, Kubik, and Abernathey (1990) were used to identify relevant anatomical landmarks.

\section{Behavioral Analysis}

Mean RTs and ERs measured during the scanning test were analyzed separately and considered as independent variables of a $2 \times 7$ repeated-measures ANOVA with a main effect of task (2 levels: MI, VI) and a main effect of rotation ( 7 levels: $0^{\circ}$ to $180^{\circ}$, in $30^{\circ}$ steps). Subjects were considered as a random factor. Alpha level was set at $p<.05$, Greenhouse-Geisser corrected where applicable.

Means and standard deviations of EMG signals (35 trials) were measured for each subject during task performance for each experimental condition. Three different epochs were considered: (1) baseline period, from $0.5 \mathrm{sec}$ before stimulus presentation until stimulus presentation; (2) stimulus period, from stimulus presentation until $0.5 \mathrm{sec}$ before response execution; (3) response period, from $0.5 \mathrm{sec}$ before response execution until $0.2 \mathrm{sec}$ afterwards. Variability (standard deviation) of the EMG signal collected during stimulus and response periods was normalized to the EMG variability measured during baseline, on a trial-by-trial basis. This procedure allowed us to quantify changes in EMG signal across epochs, hands, and subjects. Normalized variability of the EMG signal was considered as an independent variable of a $2 \times 2 \times 2$ univariate ANOVA with a main effect of task (2 levels: MI, VI), epoch (2 levels: stimulus period, response period), and hand (2 levels: left hand, right hand). Given the small sample size, subjects were included as a fixed factor. Alpha level was set at $p<.05$, Greenhouse-Geisser corrected where applicable.

Postural contributions to task performance were assessed by considering RTs as an independent variable of a $2 \times 7$ univariate ANOVA with a main effect of left 
hand position ( 2 levels: parallel, perpendicular [to the right hand]) and rotation (7 levels: $0^{\circ}$ to $180^{\circ}$, in $30^{\circ}$ steps). MI and VI conditions were analyzed separately. Given the small sample size, subjects were included as a fixed factor. Alpha level was set at $p<.05$, GreenhouseGeisser corrected where applicable. Correlations between behavioral and neural effect size (Figure 4) were assessed by investigating Pearson correlations, onetailed, with alpha level set at $p<.05$.

\section{Acknowledgments}

Authors' contribution: experimental design (F. dL., P. H., I. T.), data collection (F. dL.), data analysis (F. dL., I. T.), manuscript preparation (F. dL., P. H., I. T.). F. dL. was supported by the ME Funds. We thank Paul Gaalman for his expert assistance during scanning; P. Fries, K. M. Petersson, K. E. Stephan, M. G. H. Coles, and H. Bekkering for invaluable discussions and comments.

Reprint requests should be sent to Floris P. de Lange, F.C. Donders Centre for Cognitive Neuroimaging, University of Nijmegen, NL-6500 HB Nijmegen, The Netherlands, or via e-mail: floris.delange@fcdonders.ru.nl.

The data reported in this experiment have been deposited in the fMRI Data Center (www.fmridc.org). The accession number is 2-2004-1179A.

\section{REFERENCES}

Alivisatos, B., \& Petrides, M. (1997). Functional activation of the human brain during mental rotation. Neuropsychologia, 35, 111-118.

Amedi, A., Jacobson, G., Hendler, T., Malach, R., \& Zohary, E. (2002). Convergence of visual and tactile shape processing in the human lateral occipital complex. Cerebral Cortex, 12, 1202-1212.

Amunts, K., Malikovic, A., Mohlberg, H., Schormann, T., \& Zilles, K. (2000). Brodmann's areas 17 and 18 brought into stereotaxic space-Where and how variable? Neuroimage, 11, 66-84.

Ashburner, J., \& Friston, K. (1997). Multimodal image coregistration and partitioning-A unified framework. Neuroimage, 6, 209-217.

Ashburner, J., \& Friston, K. J. (1999). Nonlinear spatial normalization using basis functions. Human Brain Mapping, 7, 254-266.

Ashe, J., \& Georgopoulos, A. P. (1994). Movement parameters and neural activity in motor cortex and area 5. Cerebral Cortex, 4, 590-600.

Barash, S., Bracewell, R. M., Fogassi, L., Gnadt, J. W., \& Andersen, R. A. (1991). Saccade-related activity in the lateral intraparietal area: I. Temporal properties; comparison with area 7a. Journal of Neurophysiology, 66, 1095-1108.

Berman, R. A., Colby, C. L., Genovese, C. R., Voyvodic, J. T., Luna, B., Thulborn, K. R., \& Sweeney, J. A. (1999). Cortical networks subserving pursuit and saccadic eye movements in humans: An FMRI study. Human Brain Mapping, 8, 209-225.

Binder, J. R., Frost, J. A., Hammeke, T. A., Bellgowan, P. S., Rao, S. M., \& Cox, R. W. (1999). Conceptual processing during the conscious resting state. A functional MRI study. Journal of Cognitive Neuroscience, 11, 80-95.
Blakemore, S. J., Wolpert, D. M., \& Frith, C. D. (2002). Abnormalities in the awareness of action. Trends in Cognitive Sciences, 6, 237-242.

Bonda, E., Petrides, M., Frey, S., \& Evans, A. (1995). Neural correlates of mental transformations of the body-in-space. Proceedings of the National Academy of Sciences, U.S.A., 92, 11180-11184.

Boussaoud, D., Ungerleider, L. G., \& Desimone, R. (1990). Pathways for motion analysis: Cortical connections of the medial superior temporal and fundus of the superior temporal visual areas in the macaque. Journal of Comparative Neurology, 296, 462-495.

Bremmer, F., Schlack, A., Shah, N. J., Zafiris, O., Kubischik, M., Hoffmann, K.-P., Zilles, K., \& Fink, G. R. (2001). Polymodal motion processing in posterior parietal and premotor cortex: A human fMRI study strongly implies equivalencies between humans and monkeys. Neuron, 29, 287-296.

Bridgeman, B., Gemmer, A., Forsman, T., \& Huemer, V. (2000). Processing spatial information in the sensorimotor branch of the visual system. Vision Research, 40, 3539-3552.

Carpenter, P. A., Just, M. A., Keller, T. A., Eddy, W., \& Thulborn, K. (1999). Graded functional activation in the visuospatial system with the amount of task demand. Journal of Cognitive Neuroscience, 11, 9-24.

Cohen, M. S., Kosslyn, S. M., Breiter, H. C., DiGirolamo, G. J., Thompson, W. L., Anderson, A. K., Brookheimer, S. Y., Rosen, B. R., \& Belliveau, J. W. (1996). Changes in cortical activity during mental rotation. A mapping study using functional MRI. Brain, 119, 89-100.

Colby, C. L. (1998). Action-oriented spatial reference frames in cortex. Neuron, 20, 15-24.

Colby, C. L., Gattass, R., Olson, C. R., \& Gross, C. G. (1988). Topographical organization of cortical afferents to extrastriate visual area PO in the macaque: A dual tracer study. Journal of Comparative Neurology, 269, 392-413.

Connolly, J. D., Goodale, M. A., Desouza, J. F., Menon, R. S., \& Vilis, T. (2000). A comparison of frontoparietal fMRI activation during anti-saccades and anti-pointing. Journal of Neurophysiology, 84, 1645-1655.

Connolly, J. D., Goodale, M. A., Menon, R. S., \& Munoz, D. P. (2002). Human fMRI evidence for the neural correlates of preparatory set. Nature Neuroscience, 5, 1345-1352.

Crammond, D. J., \& Kalaska, J. F. (1989). Neuronal activity in primate parietal cortex area 5 varies with intended movement direction during an instructed-delay period. Experimental Brain Research, 76, 458-462.

Crammond, D. J., \& Kalaska, J. F. (2000). Prior information in motor and premotor cortex: Activity during the delay period and effect on pre-movement activity. Journal of Neurophysiology, 84, 986-1005.

de Lange, F. P., Hagoort, P., \& Toni, I. (2003a). Differential fronto-parietal contributions to visual and motor imagery. Organization for Human Brain Mapping, 1064.

de Lange, F. P., Hagoort, P., \& Toni, I. (2003b). Visual and motor imagery: How distinct are they? Cognitive Neuroscience Society, 65, B122.

Decety, J., Chaminade, T., Grezes, J., \& Meltzoff, A. N. (2002). A PET exploration of the neural mechanisms involved in reciprocal imitation. Neuroimage, 15, 265-272.

Deiber, M. P., Ibanez, V., Sadato, N., \& Hallett, M. (1996). Cerebral structures participating in motor preparation in humans: A positron emission tomography study. Journal of Neurophysiology, 75, 233-247.

D'Esposito, M., Ballard, D., Zarahn, E., \& Aguirre, G. K. (2000). The role of prefrontal cortex in sensory memory and motor preparation: An event-related fMRI study. Neuroimage, 11, $400-408$. 
Downing, P. E., Jiang, Y., Shuman, M., \& Kanwisher, N. (2001). A cortical area selective for visual processing of the human body. Science, 293, 2470-2473.

Dukelow, S. P., DeSouza, J. F. X., Culham, J. C., van den Berg, A. V., Menon, R. S., \& Vilis, T. (2001). Distinguishing subregions of the human MT+ complex using visual fields and pursuit eye movements. Journal of Neurophysiology, 86, 1991-2000.

Duvernoy, H. M., Cabanis, E. A., \& Vannson, J. L. (1991). The buman brain: Surface, three-dimensional sectional anatomy and MRI. Wien: Springer-Verlag.

Fogassi, L., Gallese, V., Fadiga, L., Luppino, G., Matelli, M., \& Rizzolatti, G. (1996). Coding of peripersonal space in inferior premotor cortex (area F4). Journal of Neurophysiology, 76, 141-157.

Friston, K. J., Ashburner, J., Frith, C. D., Poline, J. B., Heather, J. D., \& Frackowiak, R. S. (1995). Spatial registration and normalization of images. Human Brain Mapping, 3, 165-189.

Friston, K. J., Holmes, A. P., \& Worsley, K. J. (1999). How many subjects constitute a study? Neuroimage, 10, 1-5.

Friston, K. J., Holmes, A. P., Poline, J. B., Grasby, P. J., Williams, S. C., Frackowiak, R. S., \& Turner, R. (1995). Analysis of fMRI time-series revisited. Neuroimage, 2, 45-53.

Friston, K. J., Holmes, A. P., Price, C. J., Buchel, C., \& Worsley, K. J. (1999). Multisubject fMRI studies and conjunction analyses. Neuroimage, 10, 385-396.

Friston, K. J., Holmes, A. P., Worsley, K. J., Poline, J. B., Frith, C., \& Frackowiak, R. S. (1995). Statistical parametric maps in functional imaging: A general linear approach. Human Brain Mapping, 2, 189-210.

Friston, K. J., Zarahn, E., Josephs, O., Henson, R. N., \& Dale, A. M. (1999). Stochastic designs in event-related fMRI. Neuroimage, 10, 607-619.

Garavan, H., Ross, T. J., \& Stein, E. A. (1999). Right hemispheric dominance of inhibitory control: An event-related functional MRI study. Proceedings of the National Academy of Sciences, U.S.A., 96, 8301-8306.

Genovese, C. R., Lazar, N. A., \& Nichols, T. (2002). Thresholding of statistical maps in functional neuroimaging using the false discovery rate. Neuroimage, 15, 870-878.

Gentilucci, M., Chieffi, S., Deprati, E., Saetti, M. C., \& Toni, I. (1996). Visual illusion and action. Neuropsychologia, 34, 369-376.

Gerardin, E., Sirigu, A., Lehericy, S., Poline, J. B., Gaymard, B., Marsault, C., Agid, Y., \& Le Bihan, D. (2000). Partially overlapping neural networks for real and imagined hand movements. Cerebral Cortex, 10, 1093-1104.

Goodale, M. A., Jakobson, L. S., \& Keillor, J. M. (1994). Differences in the visual control of pantomimed and natural grasping movements. Neuropsychologia, 32, 1159-1178.

Graziano, M. S., Andersen, R. A., \& Snowden, R. J. (1994). Tuning of MST neurons to spiral motions. Journal of Neuroscience, 14, 54-67.

Graziano, M. S., Cooke, D. F., \& Taylor, C. S. (2000). Coding the location of the arm by sight. Science, 290, 1782-1786.

Graziano, M. S., \& Gandhi, S. (2000). Location of the polysensory zone in the precentral gyrus of anesthetized monkeys. Experimental Brain Research, 135, 259-266.

Graziano, M. S., Hu, X. T., \& Gross, C. G. (1997). Visuospatial properties of ventral premotor cortex. Journal of Neurophysiology, 77, 2268-2292.

Graziano, M. S., Taylor, C. S., \& Moore, T. (2002). Complex movements evoked by microstimulation of precentral cortex. Neuron, 34, 841-851.
Hadland, K. A., Rushworth, M. F., Passingham, R. E., Jahanshahi, M., \& Rothwell, J. C. (2001). Interference with performance of a response selection task that has no working memory component: an rTMS comparison of the dorsolateral prefrontal and medial frontal cortex. Journal of Cognitive Neuroscience, 13, 1097-1108.

Hommel, B., Musseler, J., Aschersleben, G., \& Prinz, W. (2001). The Theory of Event Coding (TEC): A framework for perception and action planning. Behavioral and Brain Sciences, 24, 849-878.

Iacoboni, M., Koski, L. M., Brass, M., Bekkering, H., Woods, R. P., Dubeau, M. C., Mazziotta, J. C., \& Rizzolatti, G. (2001). Reafferent copies of imitated actions in the right superior temporal cortex. Proceedings of the National Academy of Sciences, 98, 13995-13999.

Jeannerod, M. (1994). The representing brain: Neural correlates of motor intention and imagery. Behavioral and Brain Sciences, 17, 187-245.

Jeannerod, M. (1995). Mental imagery in the motor context. Neuropsychologia, 33, 1419-1432.

Jeannerod, M. (1997). The cognitive neuroscience of action. Oxford: Blackwell.

Johnson, M. T., Coltz, J. D., Hagen, M. C., \& Ebner, T. J. (1999). Visuomotor processing as reflected in the directional discharge of premotor and primary motor cortex neurons. Journal of Neurophysiology, 81, 875-894.

Johnson, P. B., Ferraina, S., Bianchi, L., \& Caminiti, R. (1996). Cortical networks for visual reaching: Physiological and anatomical organization of frontal and parietal lobe arm regions. Cerebral Cortex, 6, 102-119.

Johnson, S. H. (2000). Thinking ahead: The case for motor imagery in prospective judgements of prehension. Cognition, 74, 33-70.

Johnson, S. H., Rotte, M., Grafton, S. T., Hinrichs, H., Gazzaniga, M. S., \& Heinze, H. J. (2002). Selective activation of a parietofrontal circuit during implicitly imagined prehension. Neuroimage, 17, 1693-1704.

Kalaska, J. F., \& Crammond, D. J. (1995). Deciding not to GO: Neuronal correlates of response selection in a GO/NOGO task in primate premotor and parietal cortex. Cerebral Cortex, 5, 410-428.

Konishi, S., Nakajima, K., Uchida, I., Kikyo, H., Kameyama, M., \& Miyashita, Y. (1999). Common inhibitory mechanism in human inferior prefrontal cortex revealed by event-related functional MRI. Brain, 122, 981-991.

Kosslyn, S. M. (1996). Image and brain. Cambridge: MIT Press.

Laeng, B., \& Teodorescu, D. S. (2002). Eye scanpaths during visual imagery reenact those of perception of the same visual scene. Cognitive Science, 26, 207-231.

Maldjian, J. A., Gottschalk, A., Patel, R. S., Detre, J. A., \& Alsop, D. C. (1999). The sensory somatotopic map of the human hand demonstrated at 4 Tesla. Neuroimage, 10, 55-62.

Matelli, M., Govoni, P., Galletti, C., Kutz, D. F., \& Luppino, G. (1998). Superior area 6 afferents from the superior parietal lobule in the macaque monkey. Journal of Comparative Neurology, 402, 327-352.

McKiernan, K. A., Kaufman, J. N., Kucera-Thompson, J., \& Binder, J. R. (2003). A parametric manipulation of factors affecting task-induced deactivation in functional neuroimaging. Journal of Cognitive Neuroscience, 15, 394.

Milner, A. D., \& Dijkerman, H. C. (2001). Direct and indirect routes to visual action. In B. de Gelder, E. H. F. De Haan, \& C. A. Heywood (Eds.), Out of mind. Varieties of unconscious processing: New findings and new comparisons (pp. 241-264). Oxford: Oxford University Press. 
Milner, A. D., \& Goodale, M. A. (1995). The visual brain in action. Oxford: Oxford University Press.

Milner, A. D., Dijkerman, H. C., Pisella, L., McIntosh, R. D., Tilikete, C., Vighetto, A., \& Rossetti, Y. (2001). Grasping the past: delay can improve visuomotor performance. Current Biology, 11, 1896-1901.

Morrone, M. C., Tosetti, M., Montanaro, D., Fiorentini, A., Cioni, G., \& Burr, D. C. (2000). A cortical area that responds specifically to optic flow, revealed by fMRI. Nature Neuroscience, 3, 1322-1328.

Nichols, M. J., \& Newsome, W. T. (2002). Middle temporal visual area microstimulation influences veridical judgments of motion direction. Journal of Neuroscience, 22, 9530-9540.

Oldfield, R. C. (1971). The assessment and analysis of handedness: The Edinburgh inventory. Neuropsychologia, 9, 97-113.

Ono, M., Kubik, S., \& Abernathey, C. D. (1990). Atlas of the cerebral sulci. New York: Thieme Verlag.

Parsons, L. M. (1987). Imagined spatial transformation of one's body. Journal of Experimental Psychology. General, 116, 172-191.

Parsons, L. M. (1994). Temporal and kinematic properties of motor behavior reflected in mentally simulated action.

Journal of Experimental Psychology. Human Perception and Performance, 20, 709-730.

Paus, T. (1996). Location and function of the human frontal eye-field: A selective review. Neuropsychologia, 34, 475-483.

Petit, L., \& Haxby, J. V. (1999). Functional anatomy of pursuit eye movements in humans as revealed by fMRI. Journal of Neurophysiology, 82, 463.

Rajkowska, G., \& Goldman-Rakic, P. S. (1995). Cytoarchitectonic definition of prefrontal areas in the normal human cortex: II. Variability in locations of areas 9 and 46 and relationship to the Talairach Coordinate System. Cerebral Cortex, 5, 323-337.

Richter, W., Andersen, P. M., Georgopoulos, A. P., \& Kim, S. G. (1997). Sequential activity in human motor areas during a delayed cued finger movement task studied by time-resolved fMRI. NeuroReport, 8, 1257-1261.

Richter, W., Somorjai, R., Summers, R., Jarmasz, M., Menon, R. S., Gati, J. S., Georgopoulos, A. P., Tegeler, C., Ugurbil, K., \& Kim, S. G. (2000). Motor area activity during mental rotation studied by time-resolved single-trial fMRI. Journal of Cognitive Neuroscience, 12, 310-320.

Rizzolatti, G., \& Luppino, G. (2001). The cortical motor system. Neuron, 31, 889-901.

Rossetti, Y., \& Pisella, L. (2002). Several "vision for action" systems: A guide to dissociating and integrating dorsal and ventral functions. In W. Prinz \& B. Hommel (Eds.), Attention and performance: XIX. Common mechanisms in perception and action (pp. 62-119). Oxford: Oxford University Press.

Rowe, J. B., Toni, I., Josephs, O., Frackowiak, R. S., \& Passingham, R. E. (2000). The prefrontal cortex: Response selection or maintenance within working memory? Science, 288, 1656-1660.

Sastre-Janer, F. A., Regis, J., Belin, P., Mangin, J. F., Dormont, D., Masure, M. C., Remy, P., Frouin, V., \& Samson, Y. (1998). Three-dimensional reconstruction of the human central sulcus reveals a morphological correlate of the hand area. Cerebral Cortex, 8, 641-647.

Schaafsma, S. J., \& Duysens, J. (1996). Neurons in the ventral intraparietal area of awake macaque monkey closely resemble neurons in the dorsal part of the medial superior temporal area in their responses to optic flow patterns. Journal of Neurophysiology, 76, 4056-4068.

Schmahmann, J. D., Doyon, J., McDonald, D., Holmes, C., Lavoie, K., Hurwitz, A. S., Kabani, N., Toga, A., Evans, A., \& Petrides, M. (1999). Three-dimensional MRI atlas of the human cerebellum in proportional stereotaxic space. Neuroimage, 10, 233-260.

Sekiyama, K. (1982). Kinesthetic aspects of mental representations in the identification of left and right hands. Perception \& Psychophysics, 32, 89-95.

Shen, L., \& Alexander, G. E. (1997). Preferential representation of instructed target location versus limb trajectory in dorsal premotor area. Journal of Neurophysiology, 77, 1195-1212.

Shepard, R. N., \& Cooper, L. A. (1982). Mental images and their transformations. Cambridge: MIT Press.

Simon, S. R., Meunier, M., Piettre, L., Berardi, A. M., Segebarth, C. M., \& Boussaoud, D. (2002). Spatial attention and memory versus motor preparation: Premotor cortex involvement as revealed by fMRI. Journal of Neurophysiology, 88, 2047-2057.

Snyder, L. H., Batista, A. P., \& Andersen, R. A. (1997). Coding of intention in the posterior parietal cortex. Nature, 386, 167-170.

Thoenissen, D., Zilles, K., \& Toni, I. (2002). Differential involvement of parietal and precentral regions in movement preparation and motor intention. Journal of Neuroscience, 22, 9024-9034.

Toni, I., Schluter, N. D., Josephs, O., Friston, K., \& Passingham, R. E. (1999). Signal-, set- and movement-related activity in the human brain: An event-related fMRI study [published erratum appears in Cereb Cortex 1999 Mar;9(2):196]. Cerebral Cortex, 9, 35-49.

Toni, I., Shah, N. J., Fink, G. R., Thoenissen, D., Passingham, R. E., \& Zilles, K. (2002). Multiple movement representations in the human brain: An event-related fMRI study. Journal of Cognitive Neuroscience, 14, 769-784.

Toni, I., Thoenissen, D., \& Zilles, K. (2001). Movement preparation and motor intention. Neuroimage, 14, S110-S117.

Tootell, R. B., Reppas, J. B., Dale, A. M., Look, R. B., Sereno, M. I., Malach, R., Brady, T. J., \& Rosen, B. R. (1995). Visual motion aftereffect in human cortical area MT revealed by functional magnetic resonance imaging. Nature, 375, 139-141.

Wilkinson, D., \& Halligan, P. (2004). The relevance of behavioural measures for functional-imaging studies of cognition. Nature Reviews: Neuroscience, 5, 67-73.

Wolbers, T., Weiller, C., \& Buchel, C. (2003). Contralateral coding of imagined body parts in the superior parietal lobe. Cerebral Cortex, 13, 392-399.

Wolpert, D. M., \& Ghahramani, Z. (2000). Computational principles of movement neuroscience. Nature Neuroscience, 3, 1212-1217.

Wong, E., \& Mack, A. (1981). Saccadic programming and perceived location. Acta Psychologica, 48, 123-131. 
Copyright of Journal of Cognitive Neuroscience is the property of MIT Press and its content may not be copied or emailed to multiple sites or posted to a listserv without the copyright holder's express written permission. However, users may print, download, or email articles for individual use. 